This item was submitted to Loughborough's Research Repository by the author.

Items in Figshare are protected by copyright, with all rights reserved, unless otherwise indicated.

\title{
Designing microwave patch antennas using heterogeneous substrates
}

PLEASE CITE THE PUBLISHED VERSION

http://dx.doi.org/10.1109/EuCAP.2012.6205923

PUBLISHER

(c) IEEE

VERSION

AM (Accepted Manuscript)

LICENCE

CC BY-NC-ND 4.0

REPOSITORY RECORD

Njoku, Chinwe C., W.G. Whittow, and J.C. Vardaxoglou. 2019. "Designing Microwave Patch Antennas Using Heterogeneous Substrates”. figshare. https://hdl.handle.net/2134/10059. 
This item was submitted to Loughborough's Institutional Repository (https://dspace.lboro.ac.uk/) by the author and is made available under the following Creative Commons Licence conditions.

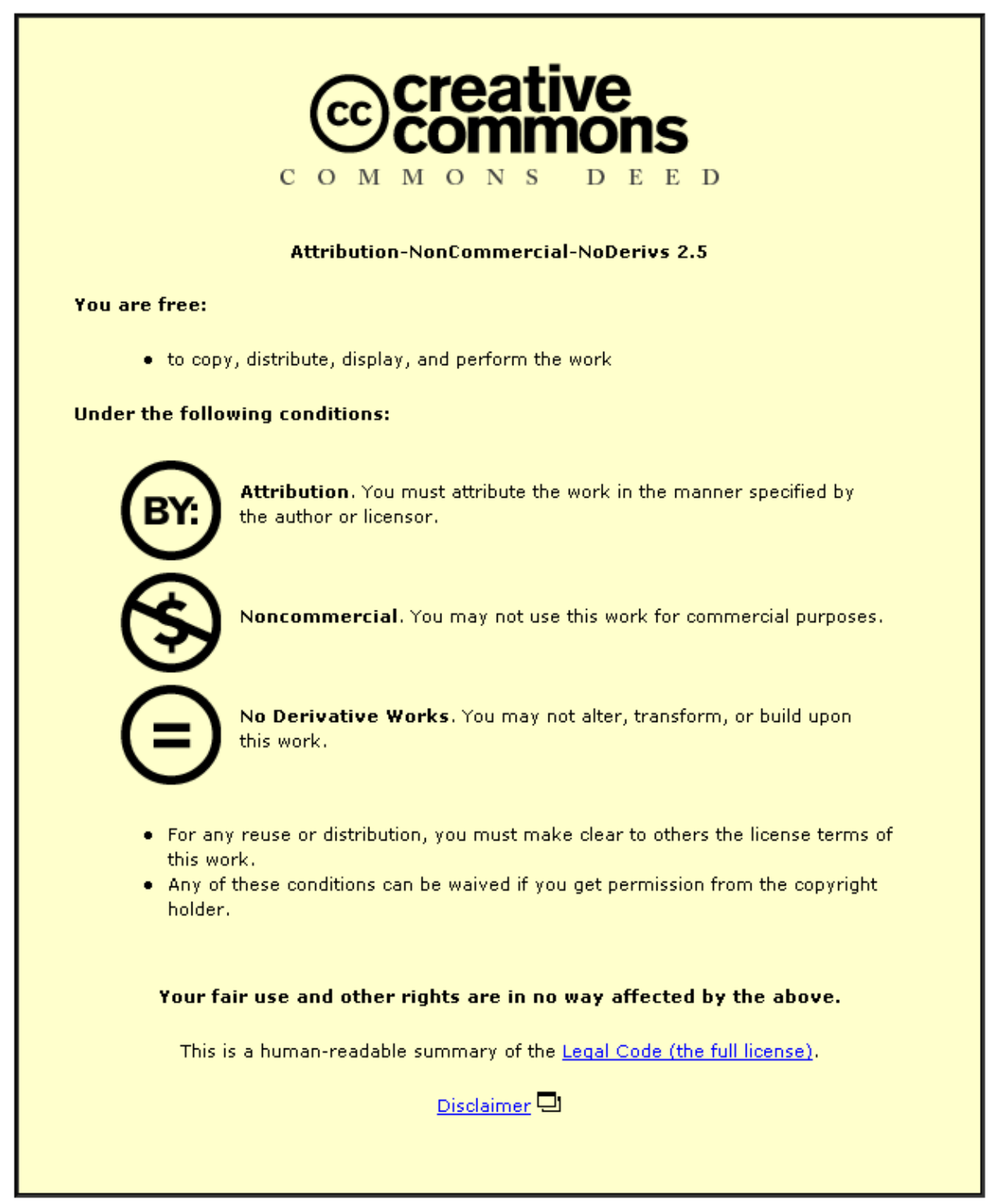

For the full text of this licence, please go to: http://creativecommons.org/licenses/by-nc-nd/2.5/ 


\title{
Designing Microwave Patch Antennas Using Heterogeneous Substrates
}

\author{
Chinwe C. Njoku, William G. Whittow, Yiannis C.Vardaxoglou \\ School of Electronic, Electrical and Systems Engineering \\ Loughborough University \\ Loughborough, UK \\ c.c.njoku@lboro.ac.uk; w.g.whittow@lboro.ac.uk; j.c.vardaxoglou@lboro.ac.uk
}

\begin{abstract}
This paper introduces the concept of designing microwave patch antennas by creating synthetic heterogeneous substrates with small scale inclusions. These inclusions embedded in a host dielectric can be used to control the dielectric properties and create bespoke effective permittivity values. Heterogeneous patch antennas at $2.4 \mathrm{GHz}$ are simulated in this paper. By deliberately mapping the permittivity values to the electric fields, the antenna behavior can be controlled and a dual band frequency was introduced. The local regions with micro-scale inclusions showed good agreement with a homogeneous substrate section with the same predicted permittivity. These heterogeneous substrates can be potentially created using nanomaterials.
\end{abstract}

Keywords: patch antenna; heterogeneous substrate; metallic inclusions; dual-band

\section{INTRODUCTION}

Antennas are vital in today's wireless world. Arguably one of the most popular geometries is the microstrip patch antenna because they are simple, cheap to make and low profile. Professor Jim James and his colleague Professor Peter Hall developed substantial quantities of knowledge about these antennas, see $[1,2]$ for more information. Antenna engineers have been building on this mountain of work ever since. However, it is becoming increasing challenging to continue to improve electromagnetic performance as is constantly demanded by manufacturers and consumers alike.

The overall idea of this work is to fabricate complete antennas systems using nanomaterials [3-6]. With the rapid development of nanotechnology, it is expected that it will soon be possible to create layered microwave antennas on the millimeter or centimeter scale where the conducting and dielectric structures are made from nanoscale structures. Such integrated processes would be additive manufacturing methods as opposed to using environmentally damaging chemicals to etch away the unwanted copper. Industrially etching printed circuit boards uses many separate processes that take at least eight hours in total.

Antenna designers are habitually hindered by having to use specific substrate permittivities, losses with specific heights. Substrates with high permittivities or low losses are often prohibitively expensive for practical products. By manufacturing the substrate and antenna in one process, it will allow the antenna engineer to choose a bespoke value of the permittivity. Furthermore these emerging nanofabrication techniques will allow antenna designers to create heterogeneous substrates.

This hypothesis of creating heterogeneous substrates is based on the theoretical work in $[7,8]$ that showed that the permittivity, permeability and conductivity can be controlled by inserting evenly spaced inclusions in a host material. The dielectric properties are then a function of the inclusion size and the spacing. Therefore, theoretically any value of permittivity $\left(<\varepsilon_{\text {inclusion }}\right)$ can be created using just two distinct materials by embedding inclusions in a host medium. This is more easily understood by examining Figure 1 where each cube represents micro-scale cuboids of nanomaterials. This methodology will allow the permittivity to be varied in all three dimensions in one fabrication process. This paper will highlight the potential improvement in electromagnetic performance that can be achieved with such small scale inclusions by examining simple heterogeneous substrates.

Previously the authors have shown that the analytical equations developed by Lewin show good agreement with electromagnetic simulations of structures exposed to plane waves [4]. The effective dielectric properties of these mixtures has also been measured showing good agreement $[4,6]$. The authors have also shown that the inclusions can be spheres or cubes and that it is the volume fraction that is critical in determining the behavior.

There has been a great deal of work varying the shape of the patch and cutting slots in the metallic section $[1,2,9]$. However, there has been relatively little research to investigate how the substrate material can be used to control antenna design. The authors have shown that a small antenna with high efficiency and bandwidth can be created by using a substrate with permeability and permittivity [10]. Future development of new synthetic materials may also allow the permeability to vary within the substrate.

Another interesting method of improving antenna performance is by using textured dielectrics [11-14]. The key idea of this work is to spread the concentration of electric fields by creating heterogeneous substrates where high permittivities are matched to areas where the electric fields are small. This

This work was supported by EPSRC under grant No. EP/101490X/1. 
produced a higher efficiency-bandwidth product compared to a homogeneous substrate. Such structures are difficult to make with current fabrication processes as typically objects of higher permittivity need to be manually located within the original substrate and hence this negates many of the manufacturing advantages of microstrip antennas. These papers used discrete heterogeneous substrates and it was hypothesized that the electromagnetic performance could be further improved by varying the permittivity smoothly.

The use of small scale inclusions enabled by advances in nanotechnology will help to solve the fabricational difficulties while allowing the electromagnetic performance to be controlled.

High $\varepsilon_{\mathrm{r}}$ region

Low $\varepsilon_{\mathrm{r}}$ region

\begin{tabular}{|c|c|c|c|c|c|c|c|c|}
\hline व व & a & ם & o & ם & a & a & a & a \\
\hline $\begin{array}{lll}0 & 0 \\
0 & 0\end{array}$ & a & व & 口 & व & 口 & & & \\
\hline $\begin{array}{l}0 \\
0 \\
0\end{array}$ & 0 & o & 口 & 0 & 口 & 口 & ० & 口 \\
\hline 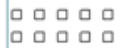 & व & ם & a & a & 口 & & & \\
\hline 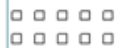 & ه & व & a & a & व & a & a & व \\
\hline 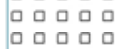 & व & ם & o & व & व & & & \\
\hline $\begin{array}{lllll}0 & 0 & 0 & 0 & 0 \\
0 & 0 & 0 & 0 & 0\end{array}$ & व & व & o & a & व & a & a & व \\
\hline $\begin{array}{lllll}0 & 0 & 0 & 0 \\
0 & 0 & 0 & 0 & 0\end{array}$ & a & a & o & a & a & & & \\
\hline 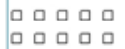 & व & 口 & 口 & a & व & a & a & 口 \\
\hline 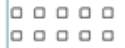 & व & व & o & व & व & & & \\
\hline 口םव & 口 & 口 & a & व & 口 & a & a & 口 \\
\hline
\end{tabular}

Figure 1. A sketch showing how the permittivity can be varied within the substrate by changing the spacing of the inclusions.

\section{ANTENNA DESIGN}

The patch antenna used in this paper had a ground plane size of $80 \times 80 \mathrm{~mm}$. The patch was $40.5 \mathrm{~mm}$ in the $\mathrm{X}$ direction and $48.4 \mathrm{~mm}$ in the $\mathrm{Y}$ direction. The original substrate was $1.524 \mathrm{~mm}$ high with a permittivity of 2.2 and a loss tangent of 0.015 . The antenna was fed with a lumped port $10.7 \mathrm{~mm}$ from the side of the patch. The antenna was simulated using EMPIRE $\mathrm{XCcel}^{\mathrm{TM}}$ finite-difference time-domain (FDTD) commercial software. As expected the maximum electric fields were found along the sides of the patch.

As an initial method of introducing an element of heterogeneity, horizontal and vertical air slots were cut in the substrate. The dimensions of the slots were $8 \mathrm{~mm} \times 56 \mathrm{~mm} \times$ $1.524 \mathrm{~mm}$, see Figure 2.

As a further comparison, the slots at the sides were replaced with a $2^{\text {nd }}$ homogeneous material $\left(\varepsilon_{\mathrm{r}}=1.4, \tan \delta=0.015\right)$. Finally, this material was replaced with 750 micron copper cubes embedded in Rohacell/air $\left(\varepsilon_{\mathrm{r}} \sim 1, \tan \delta=0\right)$, see Figure 3. Lewin's equations predict this structure to have a permittivity equal to 1.4 , see [4] for more details. Note, the remainder of the substrate could be designed using cubes of different sizes or spacings to create a dissimilar $\varepsilon_{\mathrm{r}}$ but have been modeled as homogeneous in this paper to save computational resources. Theory predicts that smaller cubes with smaller spacings would produce similar results.

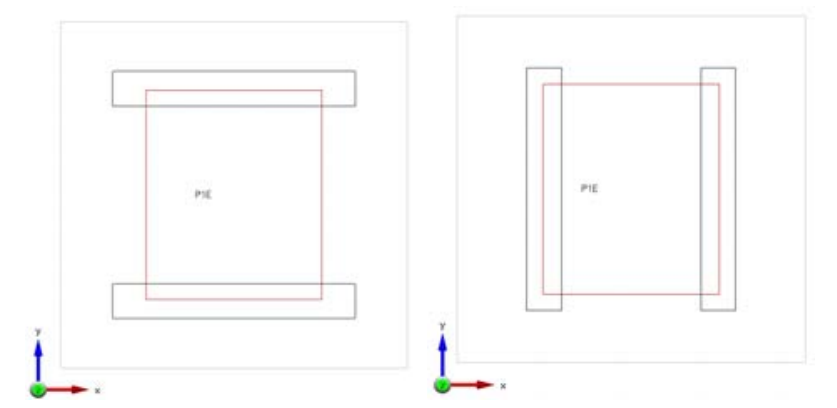

Figure 2. Patch with air slots in the substrate: (a) at top and bottom and (b) at sides

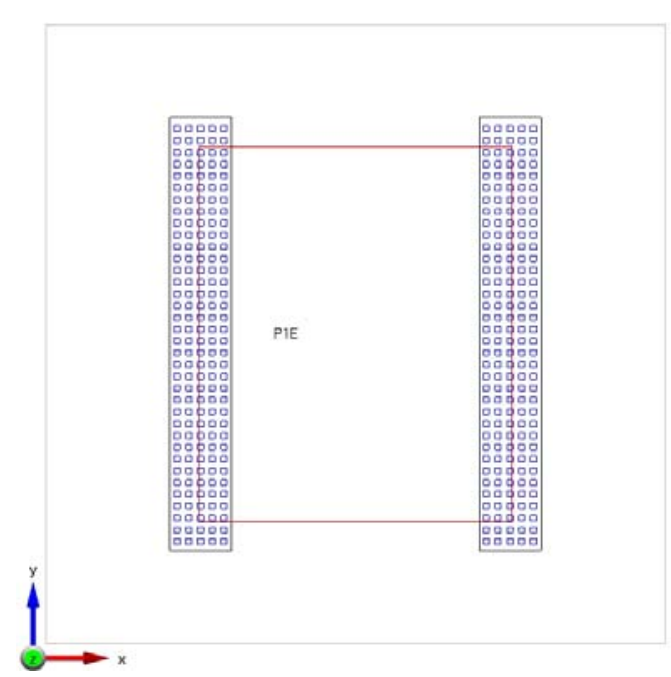

Figure 3. Patch with synthetic substrate section. Small cubes are embedded in (air) slots at the sides of the substrate.

\section{RESULTS}

Reducing the local permittivity of the substrate, decreased the dielectric loading and increased the resonant frequency. To ensure a fair comparison was made of the performance of all the antennas; in each case, the host permittivity was increased to compensate for the increase in frequency due to the lower $\varepsilon_{\mathrm{r}}$ and then the port location was moved to improve the match, see Figure 4.

Table 1 shows that adding the same sized slots at the side of the substrate (where the electric fields were largest) had a much more significant effect than when they were added at the top and bottom of the patch. This can be seen from the required increase in the host permittivity to compensate. The implementation of heterogeneous substrates introduced a second resonance which can be controlled by varying the permittivity. 
The small metallic cubes in air which had an effective permittivity of 1.4 showed good agreement with the simple homogeneous section with $\varepsilon_{\mathrm{r}}=1.4$. Table 1 shows that the efficiency of the patch with the substrate containing small cubes was slightly better than with the homogeneous patch this is due to the structure being metallic cubes in the lossless air / Rohacell host. Note, in [4], a patch was simulated with evenly spaced small inclusions throughout the entire substrate. This paper also suggested that use of the inclusions to control the permittivity did not reduce the antenna efficiency.

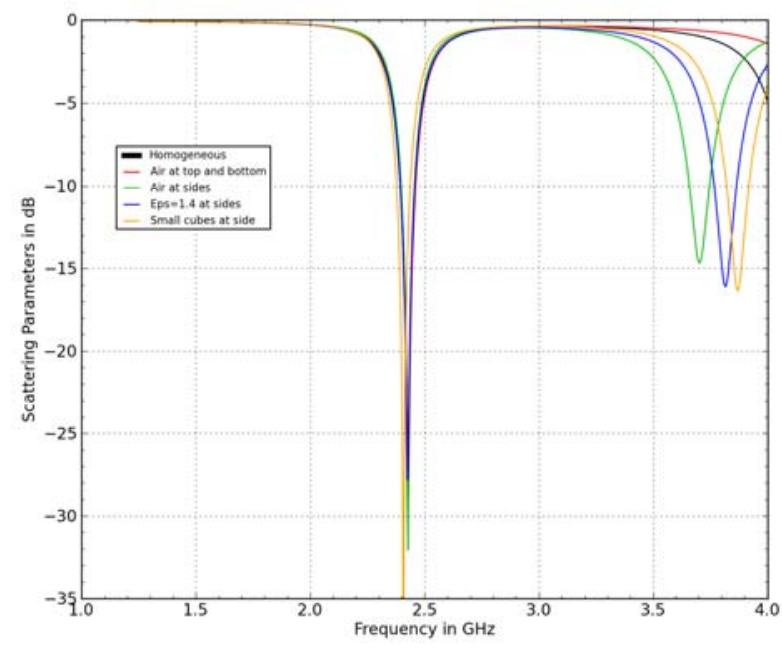

Figure 4. The return loss of the different antennas

Table 1. Simulated performance of antennas

\begin{tabular}{|c|c|c|}
\hline Description & $\begin{array}{c}\text { Required } \\
\text { permittivity of host } \\
\text { to tune to } 2 . \mathbf{G H z}\end{array}$ & Efficiency at $\mathbf{2 . 4 G H z}$ \\
\hline Homogeneous & 2.2 & $50.6 \%$ \\
\hline $\begin{array}{c}\text { Air at top and } \\
\text { bottom }\end{array}$ & 2.41 & $51.4 \%$ \\
\hline Air at sides & 3.12 & $51.4 \%$ \\
\hline Er = 1.4 at sides & 2.85 & $48.7 \%$ \\
\hline Small cubes at sides & 2.85 & $51.9 \%$ \\
\hline
\end{tabular}

\section{CONCLUSIONS}

This paper has demonstrated how varying the local permittivity value across the substrate can be used to control the electromagnetic performance of patch antenna. The paper has also demonstrated that small scale inclusions can be used for dielectric substrates and that the theoretical equations accurately predict the effective permittivity.

By mapping the local permittivity to the electric fields, the altered dielectric loading can be used to influence the antenna design and can enable multiband performance. The permittivity of the substrate where the electric fields is largest is particularly critical.

Note in this paper, only two permittivity regions were used and no attempt was made to optimize the permittivity map. In the previous works concerning textured dielectrics, the efficiency-bandwidth product was increased by using complex $3 \mathrm{D}$ shapes and the emerging nanofabrication techniques will enable these heterogeneous substrates with micro-sized cubes where the local permittivity can be controlled by the cube spacing to produce any bespoke value.

\section{REFERENCES}

J. R. James and P. S. Hall, Handbook of Microstrip Antennas: IET, 1989.

J. R. James, P. S. Hall, and C. Wood, Microstrip Antenna Theory and Design: Peter Peregrinus Ltd, 1986.

C. C. Njoku, W. G. Whittow, and J. C. Vardaxoglou, "Study on the variation in dielectric properties of heterogeneous substrates composed of nanomaterials," presented at EUCAP 2011: The 5th European Conference on Antennas and Propagation, Rome, Italy, 2011.

C. C. Njoku, W. G. Whittow, and J. C. Vardaxoglou, "Simulation Methodology for Synthesis of Antenna Substrates with Microscale Inclusions," IEEE Trans Antennas and Propagation, vol. Accepted for publication in Nov 2011 and will be printed in 2012, 2012.

C. C. Njoku, W. G. Whittow, and J. C. Vardaxoglou, "Microwave antennas and heterogeneous substrates using nanomaterial fabrication techniques (Invited Paper)," presented at IEEE Tropical Conference on Antennas and Propagation in Wireless Communications (APWC 11), Torino, Italy, 2011.

[6] C. C. Njoku, W. G. Whittow, and Y. C. Vardaxoglou, "Effective permittivity of heterogeneous substrates with cubes in a 3D lattice," IEEE Antennas and Wireless Propagation Letters (Special Issue on Metamaterials), vol. Feb 2012, 2012.

[7] L. Lewin, "The electrical constants of a material loaded with spherical particles," Proceedings of the IEE, vol. 94, pp. 65-68, 1947.

[8] C. C. Njoku, W. G. Whittow, and J. C. Vardaxoglou, "Comparative study of nanomaterials' effective properties using canonical formulations," presented at 2010 Loughborough Antennas \& Propagation Conference (LAPC), Loughborough, UK, 2010.

[9] P. S. Hall, "The contribution of J R James to printed antennas," presented at The Second European Conference on Antennas and Propagation (EuCAP 2007) Edinburgh, UK, 2007.

[10] M. I. Kitra, C. J. Panagamuwa, P. McEvoy, J. C. Vardaxoglou, and J. R. James, "Low SAR ferrite handset antenna design," IEEE Trans Antennas and Propagation, vol. 55, pp. 1155-1164, 2007.

[11] G. Kiziltas, D. Psychoudakis, and J. L. Volakis, "Topology design optimization of dielectric substrates for bandwidth improvement of a patch antenna," Antennas and Propagation, IEEE Transactions on, vol. 51, pp. 2732-2743, 2003.

[12] C. Chen and J. L. Volakis, "Bandwidth broadening of patch antennas using nonuniform substrates," Microwave and Optical Technology Letters, vol. 47, pp. 421-423, 2005.

[13] D. Psychoudakis, Y. H. Koh, J. L. Volakis, and J. H. Halloran, "Design method for aperture-coupled microstrip patch antennas on textured dielectric substrates," Antennas and Propagation, IEEE Transactions on, vol. 52, pp. 2763-2766, 2004.

[14] D. Psychoudakis, J. L. Volakis, W. Zach, and J. W. Halloran, "Cavity-Backed Miniature Wideband UHF Circular Polarized Antenna With Textured Dielectrics," Antennas and Propagation, IEEE Transactions on, vol. 54, pp. 3586-3592, 2006. 